\title{
Recordando la fundación del Partido Comunista de Costa Rica ${ }^{1}$
}

German Chacón Araya

Instituto de Estudios Latinoamericanos

Universidad Nacional, Costa Rica

$\mathbf{P}$ ara poder hablar de este hecho histórico es necesario ver el papel de la clase proletaria costarricense; esta habría venido haciendo una resistencia sostenida especialmente desde finales del siglo XIX, cuando se da la organización de los primeros sindicatos de corte socialista, mostrando su desarrollo y organización en el $1^{\circ}$ de mayo del año 1913; por ejemplo, durante los años veinte el movimiento obrero funda la Confederación de Trabajadores Costarricenses.

Antes de 1931, los anarquistas, socialistas y comunistas venían formando a los costarricenses en la búsqueda de una mayor participación en los órganos de poder; a partir de 1930, los comunistas habrían asumido en su quehacer los tres ejes fundamentales expuestos en el artículo escrito por Lenin en 1902, titulado "Por dónde empezar", el cual se puede resumir en: "el carácter y el contenido principal de nuestra agitación política, nuestras tareas de organización

1 Discurso presentado en la Casa Sindical Calufa el 16 de junio de 2017 y en la Cátedra Manuel Mora a través de Facebook. y el plan de crear, simultáneamente y en distintas partes, una organización”.

Para la agitación se utilizó la plaza pública, la hoja suelta y la prensa, tal y como se expone en el periódico La Revolución de 1930, que en su primer número expresaba:

Es posible que en ellas (en las páginas) aparezcan con frecuencia más bien tintes negros, cuadros sombríos, voces melancólicas, gritos de dolor, porque ellas serán siempre el espejo de la sociedad de los desamparados de la suerte, por algunos llamados "parias de la civilización.

Aquí quedaba manifiesta su posición clasista y seguía diciendo en líneas posteriores:

Queremos, aunque sea a fuerza de repeticiones, porque en el campo de la verdad no es posible hacer innovaciones sustanciales, formar mentalidades apropiadas para los cimientos de las grandes instituciones del futuro. 
Se planteaba que, por un lado, la sociedad era desigual y, por otro lado, habría llegado el momento de organizarse para transformar la realidad, "Planteadas, así las cosas, las condiciones generales para el nacimiento del Partido Comunista habían alcanzado su momento. El Partido Comunista hizo surgir la lucha de clases en el plano político de manera organizada y consciente" (De la Cruz, 1981, 253). La fundación del Partido Comunista se ha fijado el 16 de junio de 1931, dado que ese día se produce la primera reunión del llamado Comité Ejecutivo del Partido Comunista de Costa Rica, que se efectúa en San José, en el local de la Unión General de Trabajadores..

El denominado Comité Ejecutivo fue constituido por: Manuel Mora Valverde, Jaime Cerdas Mora, Alfredo Valerín Acevedo, Gonzalo Montero Berry, Carlos Marín Obando, Luis Carballo Corrales, Ricardo Coto Conde.

En el acto constitutivo o fundación estuvieron: Efraín Jiménez, José Barquero, Anselmo Soto, Luisa González y María Isabel Carvajal, entre otros. Se estima, de acuerdo con datos revelados en su momento, que la agrupación tenía en todo el país aproximadamente unos 500 simpatizantes vinculados.

Habría surgido así una manera diferente de hacer política, lo cual conduciría a la creación de nuevas instituciones públicas, modificación de la constitución de 1871 , entre otros elementos que marcarían los derroteros por donde transcurriría la Costa Rica del siglo XX.
A la luz de lo expuesto, puede comprenderse mejor la originalidad que supuso el Partido Comunista en la Costa Rica durante la década de 1930; en medio de la crisis económica, emergió un empeño editorial, no visto anteriormente en el país. Las organizaciones políticas publican hojas sueltas, periódicos y libros, donde hacen denuncia de las injusticias sociales, llaman a los proletarios a aprender a leer, iniciando procesos de formación continua que permitan la organización de los trabajadores del campo y la ciudad, para lo cual en el año 1931 se refundó la Universidad Popular ${ }^{2}$ con el apoyo de la Liga Anti-imperialista, en la que ejercieron la docencia connotadas figuras como: Joaquín García Monge, Haya de la Torre, el periodista Jorge Vivós, Carmen Lyra, entre otros; asimismo entre algunas de las materias que se impartieron están: historia de la penetración imperialista en América Latina, economía política, organización sindical, entre otras. En su afán formativo, en octubre de 1931, el Partido Comunista entrega la Biblioteca Lenin a la Universidad Popular, la cual estaba conformada por aproximadamente quinientos títulos. Con lo cual se puede afirmar que los costarricenses se preparaban ideológicamente para dar una lucha en el campo de las ideas.

La crisis capitalista mundial, aparejada a un modelo de organización del Estado obsoleto y desfasado, como se expresan en las denuncias y los artículos de La Revolución, muestran un país sumido en la miseria, donde los comunistas empiezan a escribir la historia, al pensarse una sociedad nueva "socialista", a partir de la

2 "Botey, Ana María y Cisneros, Rodolfo, La crisis de 1929 y la fundación del Partido Comunista de Costa Rica, San José, Editorial Costa Rica, 1984, pp. 75-132. 
creación de un tejido partidario, que se proyectaría en el futuro del país por más de cincuenta años, lo que habría incidido en la forma de organización del Estado costarricense durante el siglo XX.

La vanguardia revolucionaria planteaba Manuel Mora Valverde, debe ser capaz de determinar en forma muy clara cuál es el "principal obstáculo" que debe vencer o el "primer objetivo" que debe proponerse la clase obrera para avanzar hacia su objetivo final el socialismo, y en la definición de las tareas que deben reflejar los intereses de todos aquellos sectores de la población que se ven objetivamente perjudicados, por la actual situación política, económica y social, es decir, de todos sus posibles aliados.

El primer programa del Partido Comunista de Costa Rica expresa los conceptos fundamentales acerca de su concepción, de la sociedad, del papel del proletariado en ella y del sistema social que eliminará la explotación del "hombre por el hombre", fija con precisión sus tareas políticas y señala las reivindicaciones más inmediatas, que son las que deben determinar el contenido de la labor de agitación parcial a favor de pequeñas reivindicaciones, tal y como aparecen recogidas en las hojas sueltas, en los programas electorales, en el periódico Trabajo y en los discursos de Manuel Mora y de los dirigentes comunistas en todos los frentes.

El Programa Mínimo del Partido Comunista, que se publicó en el periódico Trabajo del 13 de marzo de 1932, es uno de los documentos históricos menos estudiado; desde su preámbulo revela una doctrina revolucionaria y anti-imperialista que textualmente dice:
"Costa Rica es un país de economía dependiente o semicolonial, por cuanto su industria, economía y agricultura están mediatizadas por el imperialismo de los grandes países capitalistas (Estados Unidos, Inglaterra, etc.). Debido a este hecho fundamental, la implantación del programa comunista integral (abolición de la propiedad privada, socialización de los medios de producción, etc.) no se pondrá a la orden del día en el país sin haberse ya realizado la revolución social en las metrópolis de que dependemos económicamente o sin la concurrencia de factores especialísimos, que permitieran organizar la economía y la vida social del país, sobre bases totalmente comunitarias sin provocar intervenciones imperialistas

El Programa Mínimo permite ver el pragmatismo con que analizaba la realidad social el colectivo comunista. En él, exponía un conjunto de reformas sociales por alcanzar en el corto y mediano plazo, orientadas a mejorar las condiciones de vida de la clase trabajadora y desarrollar una base social que posibilitara conquistar el poder y consumar el programa máximo, es decir la conquista de la sociedad socialista. En él se esbozaba la línea política general; esa plataforma programática trazó cuestiones medulares para la época, tales como: el establecimiento de seguros sociales, a cargo del Estado; la efectividad de la jornada laboral de ocho horas; ley de salario mínimo; leyes de organización sindical y derecho de huelga; emancipación político-jurídica de la mujer; revisión de los contratos celebrados por el Estado con el capitalismo nacional y extranjero; reforma agraria; intervención del Estado en el control y explotación de recursos naturales y 
servicios públicos estratégicos; reducción del aparato burocrático; ley de casas baratas para los trabajadores; ley de servicio civil y la reforma educativa.

Por medio de las propuestas programáticas citadas, buscaban movilizar la conciencia del proletariado al asumir la particularidad como parte de una contradicción, que remite a la idea del todo, con el propósito de hacer explícita la confrontación de clase, exponiendo así un conjunto de planteamientos que llevarían a la toma del poder como fin último del proletariado ${ }^{3}$. Estas ideas no han quedado en el olvido y siguen estando vigentes y hoy en pleno siglo XXI, 86 años después de esa fundación miles de costarricense de todas las edades creen en que ese mundo soñado es posible.
3 En 1928 se fundaría la Unión General de Trabajadores, central obrera que propiciaría más tarde la vinculación con la Liga Feminista, la formación en 1926 de la Universidad Popular y, tres años más tarde, de la Asociación Revolucionaria de Cultura Obrera, en el mismo momento en que también se establecía la Alianza de Obreros, Campesinos e Intelectuales, encabezada por Joaquín García Monge y que pese a su vinculación con el APRA, guardaba también con la Liga Antiimperialista una muy cercana relación (Calvo y Zúñiga Díaz, 6: 1980).

\section{Bibliografía}

Botey, A.M y Cimeros, R. (1984). La crisis de 1929 y la fundación del partido Comunista de Costa Rica. San José: Editorial Costa Rica.

Calvo, G. y Zúñiga Díaz, F. (1980). Compilación. Manuel Mora Valverde. Discursos. San José: Editorial Presbere.

Cerdas Mora, J. (1993). La otra vanguardia - memorias. San José: Editorial EUNED.

Contreras Alvarez, G. (2010). Semblanzas de luchadores sociales del Partido Vanguardia Popular. San José: Ediciones Contemporáneas.

De la Cruz, V. (1981). Las luchas sociales en Costa Rica. San José: Editorial de la Universidad de Costa Rica.

Mora Rodríguez, A. (1999). Los orígenes del pensamiento socialista en Costa Rica. San José: Editorial DEI.

Salas, A. (1997). Con Manuel: devolver al pueblo su fuerza. San José: Editorial de la Universidad de Costa Rica.

Oliva Medina, M. (2006). Artesanos y obreros costarricenses: 1880-1940. San José: Editorial de la Universidad Estatal a Distancia. 